\title{
VIDA PROFESSORAL DE MARIA DO CARMO DE MIRANDA: DOCÊNCIA EM TEMPOS AUTORITÁRIOS (1960-1988)
}

- MARIA GRAÇA CRUZ BARBOSA

Universidade Federal da Paraíba

\section{LUCIANA MARTINS TEIXEIRA SANTOS}

Universidade Federal da Paraíba

\section{MARIA ELIZETE GUIMARÃES CARVALHO}

Universidade Federal da Paraíba

RESUMO O presente artigo tem por propósito refletir sobre os saberes docentes e a prática pedagógica, produzidos e/ou reproduzidos no período de 1964 a 1988, a partir dos resultados da pesquisa de Mestrado em Educação/PPGE/UFPB "História e Memórias de vida professoral: Maria do Carmo de Miranda nas configurações do magistério (19601988)". Conforme Nóvoa (2007), pesquisas sobre história de vida de professores se inserem como instrumentos elucidadores para a História da Educação, ao permitirem a discussão de aspectos educacionais a partir de trajetórias individuais, numa relação entre o privado e o político-social. O aporte teórico-metodológico discute com os fundamentos e procedimentos da memória, da história oral e da abordagem biográfica, articulados aos estudos de Le Goff (2012), Nóvoa (1999; 2007), Dosse (2009), entre outras fontes. No processo de constituição da docência, vida e contexto se entrelaçam, de forma que os saberes docentes e a prática pedagógica vivenciados pela Professora Maria do Carmo de Miranda, ora reforçaram, ora enfraqueceram as relações autoritárias de poder e opressão, presentes no contexto da docência paraibana no período investigado.

Palavras-chave: História de vida professoral. Saber docente. Prática pedagógica. História oral.

\section{ABSTRACT TEACHER LIFE OF MARIA DO CARMO MIRANDA: TEACHING DURING AUTHORITARIANISM TIMES (1960-1988)}

This article has the purpose to reflect on the teaching knowledges, and pedagogical practice, produced and/or reproduced during 1964 
to 1988, from the Master's search results in Education/PPGE/UFPB "História e Memórias de vida professoral: Maria do Carmo de Miranda nas configurações do magistério (1960-1988". As Nóvoa (2007), research on teachers life story fall as elucidator instrument for the History of Education to allow discussion of educational aspects from individual trajectories, a relationship between the private and the political-social. The theoretical and methodological approach includes the fundamentals and procedures of memory, oral history and biographical approach, articulated to studies of Le Goff (2012), Nóvoa (1999; 2007), Dosse (2009), among other sources. In the process of constitution of teaching, life and context intertwine, so that the teaching knowledge and pedagogical practice experienced by Maria Miranda Carmo, sometimes reinforced, sometimes weakened the authoritarian relationship of power and opression, present in the context of the paraiban history teaching at the period investigated.

Keywords: History of professorial life. Teaching knowledge. Pedagogical practice. Oral history.

\section{VIDA PROFESORAL DE MARIA DO CARMO DE MIRANDA:} DOCENCIA EN TIEMPOS AUTORITARIOS (1960-1988)

El presente artículo tiene por propósito reflexionar sobre los saberes docentes y la práctica pedagógica producidos y/o reproducidos en el periodo de 1964 a 1988, partiendo de los resultados de la pesquisa de Mestrado em Educação/PPGE/UFPB “História e Memórias de vida professoral: Maria do Carmo de Miranda nas configurações do magistério (1960-1988)". Conforme Nóvoa (2007), pesquisas sobre historia de vida de profesores se inserten como instrumentos de elucidación para la Historia de la Educación, al permitir la discusión de aspectos educacionales partiendo de trayectorias individuales, en una relación entre el privativo y el político-social. El aporte teórico-metodológico discute con los fundamentos e procedimientos de la memoria, de la historia oral y del abordaje biográfico articulados a los estudios de Le Goff (2012), Nóvoa (1999; 2007), Dosse (2009), entre otras fuentes. En el proceso de construcción de la docencia, vida y contexto se entrelazan, de forma que los saberes docentes y la práctica pedagógica vividos por la profesora Maria do Carmo de Miranda, ora reforzaron, ora debilitaron las relaciones autoritarias de poder y opresión presentes en el contexto de la docencia paraibana en el periodo investigado.

Palabras clave: Historia de vida profesoral. Saber docente. Práctica pedagógica. Historia Oral. 


\section{Introdução}

A história não é mais mistura de vista e ouvido como era para Heródoto, ou pesquisa, investigação e busca da veracidade, como foi para Tucídides, mas "questionamento da evidência" (HARTOG, 2011, p. 12-13), para além da elaboração de verdades.

Nesse movimento epistemológico, a abordagem biográfica ${ }^{1}$ retorna e a evidência oral é reabilitada, tornando-se subsídios fecundos em pesquisas no campo da História da Educação, pois permitem a articulação entre o particular e o social, abordando nas entrelinhas de uma vida aspectos de um contexto.

Nesse estudo, tomamos por referência as memórias da história de vida professoral de Maria do Carmo de Miranda, que perpassam momentos distintos da conjuntura políticosocial-econômica e educacional brasileira e paraibana, como: início dos anos 1960, quando principiou sua formação docente; 1964, na instauração da Ditadura Civil-Militar, quando passa a exercer o magistério; e 1988, período de transição e redemocratização, quando falece.

Diante da articulação entre a história de vida professoral de Maria do Carmo de Miranda e o cenário em que viveu e desenvolveu a docência (1960 a 1988), objetivamos refletir sobre os saberes docentes e as práticas pedagógicas produzidos e/ou reproduzidos pela professora durante o período de formação e atuação profissional.

Pesquisar sobre professores e suas trajetórias é, em qualquer tempo, trabalhar com um contexto muito anterior à prática em si, ao dia a dia, a vida

1 A biografia clássica preocupada em registrar a história dos grandes homens era vista como prática conservadora e desarticulada da conjuntura política, econômica, social. Assim, os historiadores das primeiras gerações dos Annalles, interessados pela história estrutural relegaram o gênero biográfico a uma condição de marginalização. O retorno da biografia acontece por volta de 1960 com os estudos de Febvre (2017) e Braudel (2016), quando discutem a história de personagens importantes, os grandes homens, em articulação com uma história problema. funcional. É levar em conta o período de formação, de 'formar para a ação', e o período ainda anterior a este, a história de vida de cada um dos sujeitos, o que os trouxe, em última instância, a preparação para e ao exercício do magistério. (ESQUISANI; WERLE, 2010, p. 106)

Nesse sentido, a investigação sobre a história de vida professoral de Maria do Carmo de Miranda tem início bem antes do exercício professoral, no período dos estudos de formação e mesmo em momentos anteriores da vida cotidiana da professora. Tal história se constitui um ponto de partida para refletirmos sobre os saberes docentes produzidos (ou reproduzidos) no decorrer dos anos 1960 a 1988, período em que Maria do Carmo de Miranda formou-se professora e atuou no magistério paraibano.

Para o enlace produtivo entre memória e biografia, a história oral apresentou-se como metodologia viável, pois através das lembranças, silêncios e/ou esquecimentos revelados na história de vida professoral de Maria do Carmo de Miranda, tivemos a possibilidade de recompor vestígios dos saberes e práticas docentes, produzidos/vivenciados no período de interesse, para interpretá-los em suas ambiguidades, equivalências, permanências e/ou descontinuidades.

Assim, para a recomposição dessa história de vida professoral, utilizamos a História Oral como metodologia, entrevistando colegas de trabalho, ex-alunos e familiares da docente, além de nos apropriarmos de fontes escritas e iconográficas, na perspectiva de compreender as configurações da docência, pela história de formação, experiências educativas e práticas pedagógicas.

\section{Saberes docentes nas memórias de formação: Professora Maria do Carmo de Miranda e o Instituto de Educação da Paraíba}

"Não nascemos professoras, nos tornamos" (FONTANA, 2007, p. 24), e nesse processo de 
constituição, em que vida e contexto se entrecruzam, a identidade professoral é configurada num movimento eclético de significados (pessoais, sociais, políticos, culturais, entre outros), a compor a pessoa do/a professor/a, e a traçar as notas do magistério.

De acordo com Nóvoa (2007), a constituição da identidade professoral transcende a disseminação de conhecimentos, para ser lugar de reflexão e formação, em que a construção de saberes e práticas são constituídos do "ponto de vista teórico e metodológico, dando origem à construção de um conhecimento profissional docente" (NÓVOA, 2007, p. 4).

Para construir sua identidade professoral, a Professora Maria do Carmo de Miranda buscou o Instituto de Educação da Paraíba (IEP), onde cursou o ensino normal, numa época em que o magistério, de acordo com o art. 52, da LDB Lei 4.024/1961, "tinha por finalidade a formação de professores, orientadores, supervisores e administradores escolares destinados ao ensino primário, e o desenvolvimento dos conhecimentos técnicos relativos à educação da infância" (BRASIL, 2012a); quiçá para adquirir independência (social, financeira) ou simplesmente formar-se professora. É o que nos revelam as memórias de Santos (2013):

Quando ela [Maria do Carmo de Miranda] terminou o ginasial foi fazer pedagógico, aí por ela ter vindo fazer pedagógico e continuar desse mesmo jeito indo pra Cabedelo todo dia, a gente veio morar em João Pessoa, por conta dela querer fazer o pedagógico. Foi quando ela foi estudar no IEP. Na época se chamasse IEP ninguém conhecia, tinha que chamar Escola de Formação de Professores, você não chamava IEP, era Escola de Formação de Professores. (SANTOS, 2013, p. 3)

Nessas memórias, percebe-se o desejo e a determinação da Professora Maria do Carmo de Miranda em cursar o pedagógico numa sociedade conservadora como a paraibana, mas também o apoio da família, que, para fa- cilitar a realização do Curso no IEP, se muda da cidade de Cabedelo/PB² para João Pessoa/ $\mathrm{PB}$, pois, menos distante da escola, Maria do Carmo teria mais tempo para estudar e os cuidados com a jovem de dezoito anos, de certa forma, seriam menores.

Outro aspecto presente na memória de Santos (2013), e que ressaltamos, diz respeito à representação social que caracterizava o IEP como uma instituição de ensino de referência, era a Escola de Formação de Professores. Indícios de que, nesse momento, a docência era uma profissão importante para a mulher, implicando em respeito e prestígio no meio social para aquelas que a exerciam.

Essa conotação de formar para uma profissão respeitável configurava os Institutos de Educação em escolas diferenciadas, de renome e reconhecimento social. Essa situação estava articulada à ampliação e concepção dos institutos de educação em centros de excelência e a formação docente para o exercício do magistério em profissão que demandava status social. Conforme Veiga (2007, p. 284, grifo nosso):

A Lei Orgânica do Ensino Normal de $1946^{3}$ determinou a ampliação do número de institutos de educação como centros de excelência para a formação docente - eles reuniam jardim de infância, ensino primário, escola normal e cursos de especialização para professores (incluindo artes, música e canto) e para administradores (diretores, inspetores e orientadores educacionais).

A configuração de centro de excelência para a formação docente, atribuída ao IEP, desde os

2 Município da Região Metropolitana de João Pessoa/ PB, distante da capital $\mathbf{1 3} \mathbf{~ k m}$.

3 A Lei Orgânica do Ensino Normal de 1946 marcou o início da formação docente da Professora Maria do Carmo de Miranda. Porém, quando cursava o segundo ano da Escola Normal, entra em vigor, em 20 de dezembro de 1961, a Lei de Diretrizes e Bases da Educação (LDB), Lei no 4.024/1961, disciplinando, nos artigos 52 a 61 , a formação para o magistério, do ensino primário ao médio. (BRASIL, 2012a) 
anos de 1940, pela Lei Orgânica do Ensino Normal de 1946, configurava a escola normal enquanto espaço de excelência para a formação do/a profissional professor/a, mas também representava o espaço de formação da mulher para além do casamento ou da família, pois:

Para as professoras primárias da primeira metade do século XX, o magistério foi o ponto de partida, foi o possivel no momento histórico em que viveram. Significou o trânsito do invisível para a visibilidade e a realização de algo que não fosse o único e prestigiado serviço doméstico, como reduto privilegiado da feminilidade. 0 magistério era o trabalho intelectual e assalariado sem conotação pejorativa. (ALMEIDA, 2006, p. 81)

No entanto, essa compreensão do magistério para além do reduto do lar ou do casamento entrou em conflito com as permanências históricas da feminização do magistério. Conforme nos revelam as memórias de Santos (2013):

Era uma escola de formação de professores, porque você aprendia tudo, você aprendia assim a bordar, tinha uma professora de Artes que até cadeira de balanço as meninas faziam. Era bordar, a fazer quebra luz [abajur]. (SANTOS, 2013, p. 4)

Nessas lembranças, a formação profissional das professorandas dividia espaço com o desenvolvimento das habilidades manuais do bordado, dos objetos decorativos da casa, situação que reafirma nossa compreensão de que a conotação da educação feminina voltada para o lar ainda marcava o imaginário social da Paraíba, na segunda metade do século $X X$, e o currículo das escolas de formação.

Envolvida nesse ecletismo de sentidos que permeava o magistério, a Professora Maria do Carmo de Miranda foi construindo sua identidade professoral, bem como seu fazer pedagógico. É o que percebemos nas palavras da colaboradora:
Ela [Maria do Carmo de Miranda] nunca se interessou por essas coisas que ensinava a bordar, era passadeira, tamanco, bolsa, mas era muito dificil ela fazer alguma coisa assim. Ela fazia material pedagógico, era historinha sanfonada, eu lembro que ela comprava o livro, aí abria o livro todo e colocava um durex que era colorido, aí fazia aquela historinha. Muito material ela tinha. (SANTOS, 2013, p. 4)

Nessas lembranças, encontramos os vestígios de que os interesses da Professora Maria do Carmo de Miranda se sobrepunham ao significado conservador que envolvia a formação feminina para ser "boa esposa e mãe".

De acordo com Almeida (2006), o ideário de uma educação voltada para o casamento e para a maternidade atravessava as linhas do tempo. Assim, a escola normal paraibana encontrava-se envolvida por uma ideologia masculina e conservadora, fomentando uma formação que capacitava as normalistas para além de serem professoras, mas para futuras esposas e boas mães, capazes "de ajudar o próprio filho nas tarefas escolares".

Apesar das conquistas efetivadas ao longo das primeiras décadas do século XX, como o acesso das mulheres ao ensino superior e a algumas profissões, esses ideais, da mulher educada dentro das aspirações masculinas de boa esposa e mãe, permaneceriam, por longo tempo impregnando a mentalidade brasileira e esculpindo uma figura de mulher plasmada nesse perfil. A ideia de alocar às mulheres a sagrada missão de educar transitou por décadas no imaginário social. (ALMEIDA, 2006, p. 71)

Nesse sentido, representações de uma educação feminina tecida sob os ideais patriarcalistas de obediência e submissão da mulher à família e ao casamento delegaram, para a educação do século XIX, a tarefa de educar filhas obedientes e esposas exemplares. Os resquícios dessa feminização do magistério ultrapassaram as linhas do tempo, fazendo-se 
presentes na segunda metade do século XX (anos de 1960), na formação do Ensino Normal, vivenciada pela Professora Maria do Carmo de Miranda.

Nas disciplinas cursadas na Escola Normal, a Professora Maria do Carmo de Miranda demonstrou ser uma aluna aplicada, principalmente em Português, Religião, Prática do
Ensino, Artes Aplicadas, Psicologia, Higiene Sanitária e Canto Orfeônico, em que manteve notas entre 90 (noventa) e 100 (cem). Seu desempenho aponta responsabilidade e desejo em formar-se professora, pois em sua maioria eram notas acima da média, tendo em vista que nessa época a nota mínima exigida para aprovação era 50 (cinquenta).

Quadro 1: Disciplinas do Instituto de Educação da Paraíba. Curso de Formação de Professores Primários (1960 a 1962)

\begin{tabular}{|l|l|l|}
\hline \multicolumn{1}{|c|}{ 1o Ano (1960) } & \multicolumn{1}{|c|}{ 2o Ano (1961) } & 3o Ano (1962) \\
\hline Português & Português & História da Educação \\
\hline Matemática & História da América & Sociologia Educacional \\
\hline $\begin{array}{l}\text { Geografia e História da } \\
\text { Paraíba }\end{array}$ & Filosofia & Psicologia Educacional \\
\hline Geografia da América & Psicologia & Prática de Ensino \\
\hline Educação Física & Prática de Ensino & Metodologia do Ensino Primário \\
\hline Anatomia & Metodologia & Higiene e Puericultura \\
\hline Física & Higiene Sanitária & Música e Canto Orfeônico \\
\hline Química & Canto Orfeônico & Desenho \\
\hline Desenho & & Educação Física, Recreação e Jogos \\
\hline & Educação Física & Artes Aplicadas \\
\hline Artes Aplicadas & Artes Aplicadas & Religião \\
\hline & Religião & \\
\hline
\end{tabular}

Fonte: Arquivo do Instituto de Educação da Paraíba (IEP). ${ }^{4}$

As disciplinas de "higiene sanitária" e "higiene e puericultura", presentes no segundo e terceiro anos de formação da Professora Maria do Carmo de Miranda, estavam articuladas aos princípios higienistas de introdução de novos hábitos de higiene favoráveis à formação da sociedade civilizada dos primeiros anos da República.

Tais hábitos tinham uma forte conotação moralista, pois a ausência de higiene estava

40 arquivo do IEP fica localizado no prédio da própria escola, situado à Avenida Camilo de Holanda, Centro, s/n, João Pessoa/PB. CEP: 58013-360. associada à pobreza, à ignorância. De acordo com Veiga (2007, p. 267), “Nas escolas normais o conteúdo do higienismo em disciplinas permaneceu em todo período aqui estudado (1889-1971), alterando a nomenclatura: higiene e fisiologia, puericultura, até se consolidar como biologia educacional". Mudava-se apenas o nome da disciplina, mas seus princípios permaneciam pouco alterados.

Nessa tessitura, entre representações e normatizações, a profissão docente lapidava a identidade pessoal das normalistas, inclusive da Professora Maria do Carmo de Miranda, 
para constituir a identidade professoral desse momento, início dos anos sessenta, do século passado.

Ora, nesse período, as Escolas Normais eram regidas pela Lei Orgânica do Ensino Normal, decreto-lei no 8.530 , de 2 de janeiro de 1946, que oficializara o ensino normal mediante as seguintes finalidades: "Prover a formação do pessoal docente necessário às escolas primárias. Habilitar administradores escolares destinados às mesmas escolas. Desenvolver $\mathrm{e}$ propagar os conhecimentos e técnicas relativas à educação da infância" (ROMANELLI, 1983, p. 164).

Pedagogicamente, o curso normal estava configurado em disciplinas de cunho geral e específico, de forma a atender a Lei Orgânica do Ensino Normal, decreto-lei no 8.530/1946, e aos parâmetros estabelecidos pela Lei de Diretrizes e Bases da Educação Nacional (LDBEN), Lei no 4.024/1961.

A Lei Orgânica do Ensino Normal prescrevia, em seu artigo 14 , que os programas das disciplinas do curso normal deveriam contemplar os seguintes aspectos:

a) adoção de processos pedagógicos ativos;

b) a educação moral e cívica não deverá constar de programa específico, mas resultará do espírito e da execução de todo ensino;

c) nas aulas de metodologia deverá ser feita e explicação sistemática dos programas de ensino primário, seus objetivos, articulação da matéria, indicação dos processos e formas de ensino, e ainda a revisão do conteúdo desses programas, quando necessário;

d) a prática de ensino será feita em exercícios de observação e participação real no trabaIho docente, de tal modo que nela se integrem os conhecimentos teóricos e técnicos de todo o curso;

e) as aulas de desenho e artes aplicadas, música e canto, e educação física, recreação e jogos, na última série de cada curso com- preenderão a orientação metodológica de cada uma dessas disciplinas, no grau primário. (BRASIL, 2012b, p. 3)

Dessa forma, o Ensino Normal era direcionado visando aos princípios pedagógicos elencados pelo ideário escolanovista, de uma educação pública que precisava ser reconfigurada para atender aos princípios liberais de desenvolvimento.

O fato da Lei Orgânica do Ensino Normal ter sido elaborada durante a ditadura Vargas, e promulgada após sua deposição, já no período de redemocratização, manifesta dois espíritos no currículo da escola normal: o autoritário/conservador, através das disciplinas de Canto Orfeônico, Higiene e Puericultura; mas também o democrático, quando incorpora disciplinas de fundamentos educacionais, como História da Educação, Sociologia, Filosofia.

Mediante essas competências de progresso científico, técnico, trabalho produtivo, à escola pública foi atribuída a tarefa de desenvolver a nação, pois a educação consistia nesse instrumento capaz de "conscientizar" a sociedade, e fazê-la avançar em busca desse "desenvolvimento social".

Diante desses preceitos, as disciplinas da Escola Normal, bem como as disciplinas ensinadas no IEP, desempenhavam um papel preponderante de "formar" a sociedade brasileira mediante o princípio "democratizante" e liberal da escola nova, retomado através do Manifesto dos Educadores Mais Uma Vez Convocados, lançado em 1959.

Dessa forma, pautadas pelos princípios escolanovistas de uma educação centrada no aluno, na experiência e em seu desenvolvimento integral, as professorandas do IEP construíam materiais didáticos, objetos concretos, inclusive Maria do Carmo de Miranda, conforme nos mostra as memórias de sua irmã, Santos (2013): “Todo material dela era didático, ela 
tinha muito material, era história sanfonada, entre outras coisas" (SANTOS, 2013, p. 4). A confecção de recursos didáticos concretos partia da compreensão de que para a escola ativa o aluno deveria experimentar, de forma que o contato com materiais didáticos promovia o processo de aprendizagem de forma participativa e prazerosa.

A Escola Nova propunha uma reconfiguração nas formas de ensinar e aprender, em que a interação do educando com seu processo de aprendizagem, a compreensão do desenvolvimento da infância de acordo com estágios psicológicos e a metodologia de projetos, entre outras situações, viabilizavam o contato do aluno com o concreto da experiência.

Para atender aos princípios escolanovistas de um ensino ativo, as disciplinas cursadas pela Professora Maria do Carmo de Miranda, e demais alunas da Escola Normal, nos anos de 1960, estavam inseridas no currículo do 2o ciclo da Escola Normal. A formação de professores primários estava estruturada em matérias diversificadas e de formação mais especializada. Os objetivos encontravam-se implícitos nas orientações da Lei de Diretrizes e Bases da Educação, Lei no 4. 024/1961, que consolidava a educação nacional mediante os seguintes princípios:

Art. 1ㅇ A educação nacional, inspirada nos princípios de liberdade e nos ideais de solidariedade humana, tem por fim:

a) a compreensão dos direitos e deveres da pessoa humana, do cidadão, do Estado, da família e dos demais grupos que compõem a comunidade;

b) o respeito à dignidade e às liberdades fundamentais do homem;

c) o fortalecimento da unidade nacional e da solidariedade internacional;

d) o desenvolvimento integral da personalida- de humana e a sua participação na obra do bem comum;

e) o preparo do indivíduo e da sociedade para o domínio dos recursos científicos e tecnológicos que thes permitam utilizar as possibilidades e vencer as dificuldades do meio;

[...]. (BRASIL, 2012a, p. 1)

Assim, inspirado por estes princípios de liberdade e solidariedade humana, o Ensino Normal, após publicação da LDB № 4.024/1961, propôs disciplinas que perpassavam os fundamentos da educação, como psicologia educacional, sociologia, metodologia e prática de ensino; e disciplinas que tratavam do fortalecimento das sensibilidades nacionalistas, a exemplo do canto orfeônico, da disciplina de higiene e puericultura. Formas implícitas do fortalecimento da unidade nacional desenvolvimentista e do conservadorismo autoritário ainda prevalecente.

Inserida nesse ideário, de uma educação liberal-democrática, e pautada pelos princípios escolanovistas, a identidade professoral, dos anos de 1960, adquiria feições liberais da formação científica e técnica do aprender $a$ aprender, e também humanistas do aprender a ser, em articulação com os ideais de liberdade e solidariedade humana.

Nesse movimento, a Professora Maria do Carmo de Miranda teceu sua identidade de professora, que se contrapunha aos resquícios da feminização do magistério, ao demonstrar pouco interesse pelas aulas de bordado e trabalhos manuais; mas, também correspondeu à educação vivenciada, sendo uma aluna aplicada com notas acima da média.

Ora, a constituição da identidade professoral não acontece de forma isolada do ambiente histórico em que se processa, mas é envolvida pelas inquietudes do contexto e desejos/trajetos de uma vida, em articulação com as representações da profissão de professor. Num 
movimento de "adesão, acção e autoconsciência" (NÓVOA, 2007, p. 16).

Assim explica Nóvoa (2007, p. 16): “O processo identitário dos professores perpassa três momentos: a adesão a princípios e valores educacionais, a acção diante das escolhas que fazemos em nossas maneiras de ensinar, e autoconsciência, que é a reflexão do professor sobre suas ações", ou seja, a "escolha", intencional ou não, pela profissão docente implica a adesão a uma concepção de educação, a ação diante da sociedade, e autoconsciência pedagógica, que é a capacidade de refletir sobre a prática.

Mediante esse processo de adesão, ação e autoconsciência, compreendemos que a identidade professoral não é constituída por imposições, mas por equacionamentos, nivelamentos entre o eu e a profissão, o que não pressupõe ser sempre um movimento harmônico, pois, nessa equação, posturas e escolhas se elaboram ou são reconstruídas, de forma que:

\begin{abstract}
A identidade é um lugar de lutas e de conflitos, é um espaço de construção de maneiras de ser e estar na profissão. Por isso, é mais adequado falar em processo identitário, realçando a mescla de dinâmica que caracteriza como cada um se sente e se diz professor. A construção de identidades passa por um processo complexo graças ao qual cada um se apropria do sentido da sua história pessoal e profissional. (NÓVOA, 2007, p. 16)
\end{abstract}

Esse aspecto de lutas e conflitos refletiu-se na Escola Normal, do início dos anos de 1960, pois a conclusão no Curso Normal, no IEP, significava o emprego garantido no serviço público. Assim, aconteceu com a Professora Maria do Carmo de Miranda, e com suas colegas de formatura. "Quando ela [Maria do Carmo de Miranda] concluiu o curso em 1962, Pedro Gondim foi o paraninfo da turma e o presente que ele deu foi a nomeação de todas as alunas. Aí ela foi trabalhar em Cabedelo" (SANTOS, 2013, p. 2).
“Esse presente" era uma prática comum na Paraíba dos anos de 1960, não apenas para a carreira de professor, mas para outros cargos públicos, pois mesmo estando presente na LDB de 1961, no Art. 60, a obrigatoriedade de concurso, "O provimento efetivo em cargo de professor nos estabelecimentos oficiais de ensino médio será feito por meio de concurso de títulos e provas" (BRASIL, 2012a, p. 15), sua realização era prática inexistente.

Essa situação demonstra o descumprimento dos governantes da época para com as determinações legais para o magistério, de forma que as contratações no serviço público aconteciam por indicação política. Tal aspecto favorecia a máquina estatal, que se eximia de garantir direitos trabalhistas e previdenciários, e enfraquecia a sociedade que se via presa a um contrato sem nenhum direito, sendo muitas vezes alvo de perseguição política.

Nesse espaço de lutas e conflitos, a Professora Maria do Carmo de Miranda, ao construir sua identidade professoral, vivenciou escolhas e (re)elaborações na sua maneira de ser e estar na profissão docente, ora divergindo, ora reforçando os princípios pedagógicos veiculados para a docência.

\section{Saberes docentes nas memórias de atuação pedagógica: a Professora Maria do Carmo de Miranda nas configurações da Ditadura Civil-Militar}

Parafraseando as palavras de Mignot (2000, p. 124), a Professora Maria do Carmo de Miranda "não guardou a vida em papéis", o que abre espaço para o campo das lembranças em que:

A memória, principal fonte dos depoimentos orais, é um cabedal infinito, onde múltiplas variáveis - temporais, topográficas, individuais, coletivas - dialogam entre si, muitas vezes re- 
velando lembranças, algumas vezes, de forma explicita, outras vezes de forma velada. (DELGADO, 2010, p. 16)

A lacuna significativa de registros escritos aponta para a necessidade de investigação de vestígios orais, indicando que a vida professoral de Maria do Carmo de Miranda foi guardada para além dos papéis, na memória individual e coletiva de suas ex-alunas, ex-colegas de trabalho e familiares. Tal fato significou o entrelaçamento de nossa pesquisa com o paradigma indiciário, no sentido de perceber os sinais, as lembranças e os indícios deixados sobre essa professora.

Os vestígios encontrados nas memórias das pessoas que conviveram com a Professora Maria do Carmo de Miranda, os rastros sobre sua formação e atuação docente "transmitem-nos às vezes um eco, mesmo que tardio e deformado" (GINZBURG, 1989, p. 151), mas que contribui para a compreensão desse percurso de vida.

Nesse sentido, buscamos nas memórias narrativas sobre a Professora os ecos das lembranças, mas também do esquecimento, "os ditos e os não-ditos", o que foi lembrado ou o que foi esquecido, fortalecendo-se o desafio de desvelar as memórias, retirar o véu do contexto que a envolveu, colocando-a protagonista de sua trajetória professoral.

Esse protagonismo diverge da versão biográfica romanceada da pessoa perfeita, pois adotamos a perspectiva da biografia hermenêutica da identidade plural de que nos fala Dosse (2009), que traz consigo a capacidade de revelar o outro, colocando-o como "protagonista de um enredo" (PASSEGGI, 2010, p. 111), e com este o esboço de uma época através das representações e narrativas que essa pessoa teceu ao longo de sua trajetória de vida.

Escrever a vida é um horizonte inacessivel, que, no entanto, sempre estimula o desejo de narrar e compreender. Todas as gerações aceitaram a aposta biográfica. Cada qual mobilizou o conjunto de instrumentos que tinha à disposição. A biografia pode ser um elemento privilegiado na reconstituição de uma época, com seus sonhos e angústias. (DOSSE, 2009, p. 11)

Partindo dessa capacidade biográfica de revelar o outro, e com este os esboços de uma época, encontramos, nas memórias de Santos (2013), as motivações que levaram a Professora Maria do Carmo de Miranda à Escola Normal de Santa Rita/PB:

Em Santa Rita, ela [Maria do Carmo de Miranda] chegou porque ela foi exonerada do Estado, por conta de ser candidata vereadora. Foi o seguinte: meu primo, José de Arimateia, era candidato a prefeito da cidade de Cabedelo e ficou colocando na cabeça dela pra ela se candidatar vereadora, porque ela tinha uma escola, um Externato particular em Cabedelo, mesmo não morando mais lá, mas trabalhava lá e colocou essa escola 'Externato Nossa Senhora do Carmo'. Ela não foi eleita, ficou suplente. (SANTOS, 2013, p. 3)

Antes de trabalhar na Escola Normal Anísio Pereira Borges, a Professora Maria do Carmo assumiu o cargo de diretora da escola pública Engenheiro Wanderley, na cidade de Cabedelo/PB. Este cargo foi o "presente de formatura" que recebeu das mãos do governador da Paraíba, Pedro Moreno Gondim. Conforme já discutido, essa era uma prática comum para a época, não sendo apenas Maria do Carmo de Miranda que recebeu esse "presente", mas as demais professorandas da turma de normalistas que se formou em 1962.

Na cidade de Cabedelo/PB, além de trabaIhar na Escola Engenheiro Wanderley, Maria do Carmo de Miranda abriu uma escola particular, em 1963, o Externato Nossa Senhora do Carmo, tendo funcionado por apenas um ano. 0 fato de ser diretora de uma escola pública e de ter uma escola particular na mesma cidade tornava a Professora Maria do Carmo de Miranda uma pessoa bastante conhecida na cidade. 
Figura1: Professora Maria do Carmo de Miranda (ao centro, em pé discursando) em Solenidade de entrega dos boletins de alunos, na cidade de Cabedelo/PB

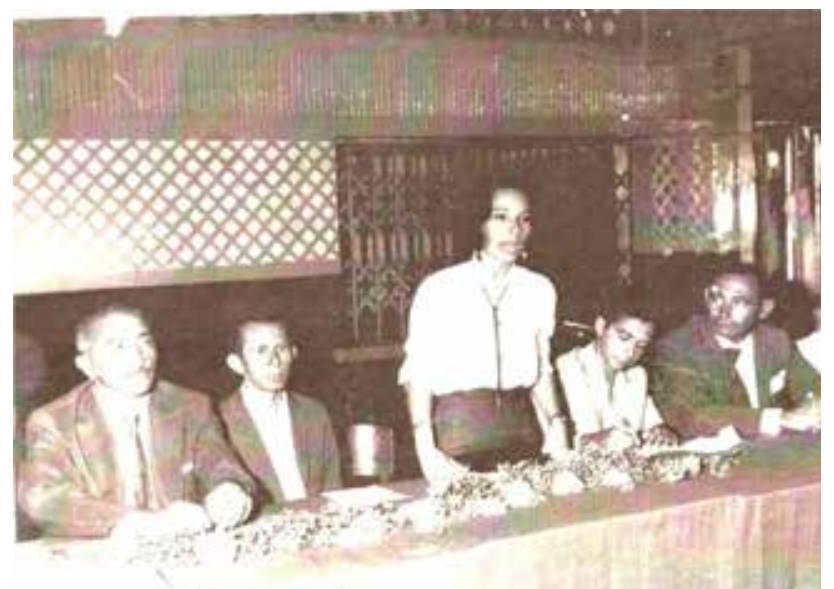

Fonte: Arquivo da família da Professora Maria do Carmo de Miranda.

Nesse sentido, justifica-se sua presença nessa solenidade em que estavam o prefeito de Cabedelo/PB, na época, o Sr. Francisco Figueiredo (o segundo à direita da Professora Maria do Carmo), seguido do Professor de desenho Latemberg (primeiro à direita da Professora), o escritor Altemar Pimentel (primeiro à esquerda), além dos alunos e seus familiares.

Conforme nos mostra a figura acima, a Professora Maria do Carmo de Miranda era a única mulher participante da mesa, situação que nos indica que a mulher, mesmo nos anos sessenta do século $X X$, ainda detinha pouco espaço na sociedade paraibana. Por outro lado, podemos perceber que a Professora Maria do Carmo de Miranda sabia como lidar com essa situação tornando o pouco espaço para o feminino um momento de abertura e de possibilidade para fazer-se conhecer diante dos homens "importantes da cidade".

As memórias de Santos (2013), irmã da Professora Maria do Carmo de Miranda, favorecem essa tese:

Ela tinha muito conhecimento em Cabedelo, das pessoas, de alunos, pais de alunos. Ela era aquela pessoa que na escola em reunião de pais o ambiente ficava completo, porque sempre em reunião de pais são pouquíssimos que frequenta[m], mas nas escolas dela não, era completo. (SANTOS, 2013, p. 3)

Esse envolvimento com os alunos, pais e demais pessoas da cidade fez da escola o espaço de relações sociais da Professora. Percebendo esse reconhecimento social/político da Professora Maria do Carmo de Miranda, seu primo, José de Arimatéia, na época, candidato a prefeito de Cabedelo/PB, convidou-a para candidatar-se a vereadora.

A Professora Maria do Carmo de Miranda aceitou o convite, e lançou candidatura em partido oposto, ao do governo do Estado da Paraíba, na época João Agripino, que era vinculado ao partido udenista. Essa situação de lançar candidatura em partido diferente do governo da época foi a motivação para que a Professora Maria do Carmo de Miranda fosse exonerada do cargo de diretora da Escola Engenheiro Wanderley.

Essa empreitada de tornar-se vereadora, ainda mais de partido oposto ao do governo, foi a razão para que Maria do Carmo de Miranda fosse retirada do quadro da Educação do Estado. Tal fato caracteriza a política paraibana dos anos de 1960, de cunho populista, com resquícios oligárquicos e partidários, em que pessoas vinculadas a partidos divergentes do que estava no poder eram, de certa forma, perseguidas, sentindo a reação da política conservadora udenista. Conforme Mello (2008):

0 esquema governamental udeno-pedencista fixou-se na dupla, João Agripino e Severino Cabral. Foi essa a última eleição com as agremiações egressas da redemocratização de 1945, suprimidas pelo Ato Institucional número dois, ainda em outubro. (MELLO, 2008, p. 232)

Diante dos reflexos da perseguição partidária após sua exoneração, a Professora Maria do Carmo de Miranda passou a lecionar em algumas escolas particulares de João Pessoa, 
como o Colégio Nossa Senhora das Neves, o Colégio João XXIII, pois mesmo não tendo vencido a eleição para vereadora em Cabedelo, ficou como suplente, no entanto, não seguiu a carreira política, pois "A política não era o que ela queria, foi mais influência" (SANTOS, 2013, p. 2).

No entanto, o mesmo "jogo político" que a exonerou, promoveu seu retorno. Era o ano de 1968, aproximadamente, quando a Professora Maria do Carmo de Miranda chega à cidade de Santa Rita/PB, para trabalhar na recém-criada Escola Normal Anísio Pereira Borges. Conforme nos falam as memórias de Santos (2013):

Quando ela tá [está] exonerada, Egídio foi lá em casa convidar para ela ir pra Santa Rita. Ela dizia não adianta porque eu fui exonerada. Ele me exonerou, como ele vai me nomear novamente. Ele disse quanto a isso não se preocupe não. Aí fez a nomeação. Egídio era o deputado que resolvia tudo lá em Santa Rita. Quando ela foi exonerada ela veio de Cabedelo, ela não tem mais nada em Cabedelo, e fica só aqui em João Pessoa, trabalhando no Colégio das Neves. Aí indicaram ela, porque Egídio tinha a Escola Normal em Santa Rita. Ela não conhecia Egídio foi uma indicação, ele que procura ela. Ele foi lá em casa chamá-la. Não foi ela que foi à procura dele. Foi ele quem foi à procura dela. Alguém indicou. Alguém indicou. (SANTOS, 2013, p. 9)

De acordo com Le Goff (2012), a memória é seletiva, portanto, voluntária ou involuntariamente, selecionamos o que lembrar e/ou esquecer. Face a essa compreensão, entendemos que, nas lembranças de Santos (2013), foi selecionado o reconhecimento social da Professora Maria do Carmo de Miranda, que é indicada por outras pessoas, de forma que foi procurada, e convidada, por uma pessoa importante da época, o deputado Egídio Madruga, para lecionar na escola normal que estava sendo criada na cidade de Santa Rita (PB).

Outra marca da seletividade da memória é a influência política abordada pela depoente, muito forte na Paraíba nesse momento, pois, mesmo a Professora Maria do Carmo de Miranda tendo sido exonerada, por conta da candidatura a vereadora na cidade de Cabedelo/PB, a influência política do deputado Egídio Madruga transforma esse quadro, conseguindo sua renomeação.

Sabemos que a política no início da República caracterizava-se pela troca de favores, estando essa evidência ainda presente e revestindo a política paraibana dos anos de 1960. Portanto, sendo a Professora Maria do Carmo de Miranda bem conhecida e respeitada na cidade, sua renomeação era também uma forma de tornar a política bem aceita pela sociedade, além de conseguir outros eleitores, configurando-se esse ato para a comunidade como representativo do prestígio político da professora Maria do Carmo.

O fato de continuar trabalhando com a educação proporcionava-lhe o contato com as pessoas, ou seja, tornava-a conhecida, lembrada, o que contribuiu para que seu nome fosse indicado para o deputado Egídio Madruga, que procurava pessoas comprometidas, para trabalhar na escola normal que estava sendo criada na cidade de Santa Rita/PB. Em 1967, a influência política desse deputado condicionou o governador João Agripino a nomeá-la para o quadro de professoras do Estado.

Nesse momento, a sociedade brasileira já vivenciava o auge da tutela do Estado Militar, e no ano seguinte à renomeação da Professora Maria do Carmo, em 1968, instaurava-se o Ato Institucional no 5 (Al-5), norma mais contundente e arbitrária do regime militar:

Na noite de 13 de dezembro de 1968, o governo anunciara, em cadeia de rádio e tv, o Al-5. O Ato inaugurou uma nova época, na política e na cultura, demarcando um corte abrupto no grande baile revolucionário da cultura brasileira, então em pleno auge. A ditadura deixou de ser 'branda', recaindo duramente sobre a parcela mais crítica da classe que ela prometia proteger e incrementar - a classe média. (NAPOLITANO, 2014, p. 118) 
Porém, toda essa ebulição política parecia não fazer parte das relações educacionais da Escola Normal de Santa Rita, bem como das práticas pedagógicas desenvolvidas pela Professora Maria do Carmo. Conforme nos revelam as memórias de Penha Oliveira: "Era muita coisa que a gente inventava. Eu me lembro que a gente inventava cursos de noite, seminários, semana de folclore, semana dos autores paraibanos" (OLIVEIRA, 2013, p. 5), pois:

Assim que chegou [em Santa Rita] ela [Maria do Carmo de Miranda] se entrosou muito bem com todo mundo, não só no trabalho em si, na profissionalização, no trabalho pedagógico, mas como pessoa mesmo. Porque Carminha tem uma facilidade muito grande de se comunicar, de se relacionar com as pessoas, então ela se relacionava muito bem com o grupo todo. (OLIVEIRA, 2013, p. 6)

Nas memórias de Oliveira (2013), a Professora Maria do Carmo de Miranda é relembrada no tempo presente: "Porque Carminha tem uma facilidade de se comunicar", embora a Professora, no momento da entrevista, já tivesse falecido há aproximadamente vinte e cinco anos. Esta situação nos indica as representações saudosas que envolvem as memórias involuntárias, e o fato de que a memória não constitui um fato real reproduzido tal como tivesse acontecido há muitos anos atrás, mas sim em representações do vivido.

Dessa forma, as lembranças de Oliveira (2013) constituem as representações que ela guardou e/ou recriou sobre os momentos de convivência com a Professora Maria do Carmo de Miranda.

Aquele que lembra não é mais o que viveu. No seu relato, há reflexões, julgamento, ressignificações do fato rememorado. Ele incorporou não só o relembrado no plano da memória pessoal, mas também o que foi preservado ao nível de uma memória social partilhada, ressignificada, fruto de uma sanção e de um trabalho coletivo. Ou seja, a memória individual se mescla com a presença de uma memória social, pois aquele que lembra, rememora em um contexto dado, já marcado por um jogo de lembrar e esquecer. (PESAVENTO, 2005, p. 94)

Nesse jogo de lembrar e esquecer, os substratos individuais e coletivos formam os "quadros sociais" (HALBWACHS, 2006) que, para se comporem, recorrem às imagens do passado apoiadas pelas convenções sociais, ou seja, mesmo tendo vivenciado experiências particulares, a retomada dessa memória traz em si o outro, de forma que "Nossas lembranças permanecem coletivas e nos são lembradas por outros, ainda que se trate de eventos em que somente nós estivemos envolvidos e objetos que somente nós vimos. Isto acontece porque jamais estamos sós" (HALBWACHS, 2006, p. 30).

Nesse sentido, as memórias de Almeida (2013) nos revelam alguns resquícios do ser professora, bem como da atividade docente desenvolvida pela Professora Maria do Carmo de Miranda na Escola Normal Anísio Pereira Borges:

Em 1970, quando eu comecei a estudar aqui, até 1972, não lembro qual era o método que a Professora 'Carminha' utilizava, mas recordo que ela sempre foi uma pessoa muito alegre, chegava bem alegre. Ela tinha um sorriso largo. Ela sorria e ao mesmo tempo em que estava sorrindo, estava te punindo por alguma coisa que não fosse correta. Mas era assim, era uma amiga. (ALMEIDA, 2013, p. 4)

Diante dessas lembranças, identificamos o retraimento e o transbordamento da memória, como nos ensina Le Goff (2012), de forma que a memória retraída se apresenta nos apagamentos, no que foi esquecido sobre a forma de ensinar da Professora Maria do Carmo de Miranda. Já a memória em transbordamento configura-se como o que ficou dessa atuação depois de tanto tempo.

Mas o que ficou e o que foi esquecido da atuação professoral de Maria do Carmo de Mi- 
randa nas memórias dessa ex-aluna? Ficaram os aspectos pessoais, o seu jeito de ser "sorridente, alegre e amiga". E foram apagados ou silenciados os vestígios da sua atuação professoral, ou seja, o que e como ensinava.

No entanto, ao lembrar que "Ela sorria e ao mesmo tempo em que estava sorrindo, estava te punindo por alguma coisa que não fosse correta", Almeida (2013, p. 5) nos revela, mesmo que de forma sutil, um vestígio da rigorosidade desse momento em que a educação era reformulada pelos parâmetros autoritários do regime militar. 0 que era correto para a educação nesse momento era justamente um ensino baseado em técnicas, ausente de reflexão ou criticidade; e a Professora Maria do Carmo de Miranda ao adotar essa postura de "punir o que não fosse correto" não agia isoladamente.

Porém, o diferencial do aspecto punitivo e corretivo da Professora Maria do Carmo de Miranda, em relação ao caráter punitivo das relações educacionais envolvidas pela conjuntura repressora da ditadura civil-militar, nesse momento, era o "sorriso", assim, envolvidas por um sorriso, as "correções" aconteciam. Porém, de que forma a Professora Maria do Carmo de Miranda conseguia que, em meio a um sorriso, suas alunas entendessem que estavam sendo "corrigidas" em algo que não fosse correto, e o que não era correto nesse momento?

Entendemos que por trás desse sorriso que corrigia estava o respeito das alunas pela Professora. Talvez não fosse o medo, mas o respeito, pois como seria possivel uma professora impor medo através de um sorriso, se esse gesto traz consigo se não a relação de amizade, ao menos uma relação mais próxima entre professor e aluno?

Talvez o sorriso na dor, como dizia o poema que tanto gostava, tentasse amenizar os temores de uma professora formada em um período de democracia, de lutas reivindicatórias, necessitando ser rigorosa, usar uma máscara, para não se trair, em tempos em que professores eram presos, processados, exilados, desaparecidos ou exonerados. Sim. Talvez fingisse, e sorria para que os males que já the tinham acontecido não se repetissem. Por que quem tinha certeza de alguma coisa em tempos de ditadura? Se antes ela tinha sido contra o governo, agora precisava fingir, usar a máscara da felicidade para dizer que estava tudo bem, que concordava com tudo. E sorria... E convidava seus alunos a sorrirem também, envolvendo-os nessa prática do sorriso. Estaria fingindo para defender-se/proteger-se?

Entre outras regulações, a ditadura civilmilitar impôs à educação um conjunto de reformas. Assim, no ano de 1971, através da Lei $5.692 / 1971$, tivemos as Reformas do ensino primário, normal e secundário, que dentre outras normatizações apontava o magistério enquanto uma das habilitações profissionais de formação do segundo grau.

Conforme constatamos nos estudos de Veiga (2007, p. 314):

A formação mínima específica dessa habilitação foi definida pelas seguintes disciplinas: fundamentos da educação (história, filosofia, e psicologia educacional); estrutura e funcionamento do ensino; didática geral; didática específica (para cada área do núcleo comum da 1a a 40 série) e estágio supervisionado.

Dessa forma, a política educacional do período estruturou a formação no magistério de segundo grau, em disciplinas que tocavam os fundamentos histórico-filosóficos e psicológicos da educação, a didática, o estágio supervisionado, em atendimento aos paradigmas tecnicistas do momento.

Nesse cenário, a Professora Maria do Carmo de Miranda desenvolveu sua prática pedagógica unindo rigorosidade, disciplina, amizade e sorriso. Conforme percebemos nas memórias de Almeida (2013): 
Como professora guardamos na memória aquela mulher forte, corajosa, guerreira que nos deixou grandes lições de vida. Semeou o amor e ensinou o significado da amizade e a importância do sorriso, pois acreditava que o sorriso era o bálsamo que acalmava. Segundo a poesia que ela admirava 'Sorria'. (ALMEIDA, 2013, p. 4)

A partir dessas lembranças, percebemos 0 movimento entre pessoa e contexto, no sentido de que a formação da identidade professoral de Maria do Carmo de Miranda permitiu-lhe inscrever em sua atuação profissional aspectos de seu modo de ser, ao ensinar a relação de amizade entre professor e aluno. E ao deixar-se ser inscrita pela subjetividade da poesia "Sorria", de forma que "A maneira como cada um de nós ensina está diretamente dependente daquilo que somos como pessoa quando exercemos o ensino. Eis-nos em face à pessoa e ao profissional, ao ser e ao ensinar" (NÓVOA, 1999, p. 17).

Diante de si e da profissão, a Professora Maria do Carmo de Miranda trouxe para a sala de aula e para suas relações na escola, sua forma de sentir e perceber o mundo. Assim, com rigorosidade e exigência ensinou que a escola deveria seguir os preceitos estabelecidos socialmente, como pontualidade, cumprimento de tarefas, entre outros:

Dona Carminha gostava de trazer coisas novas. Ela gostava de ler e trazia os livros pra gente ler, pesquisar. Ela sempre trazia alguma coisa. Durante os anos de convivência com a Professora Maria do Carmo o que mais me marcou foi o temperamento, a maneira dela de ser uma pessoa dinâmica. Uma pessoa que exigia, mas que não era aquela exigência de você ficar chateada, pois a forma dela exigir era uma maneira boa que a gente fazia as coisas sem ficar com raiva dela. Enfim, quem passou pela Escola Normal na época de Dona Carminha lembra de uma pessoa dinâmica, alegre, exigente, mas uma exigência boa, não era essa exigência arrogante. (ALMEIDA, 2013, p. 6)

Essa forma de exigir "boa" e "não arrogante" revelava o toque pessoal das conexões que a Professora Maria do Carmo de Miranda estabeleceu com o período autoritário em que exerceu a docência, que, entre outras coisas, exigia uma educação eficiente, produtiva, que cumpria prazos, controlava horários, conteúdos.

Conforme as evidências da memória:

Sua trajetória profissional nos deixou um legado de informações úteis para uma boa educação; como disciplina, pontualidade, relacionamento entre alunos e funcionários. A sua metodologia era tão própria e eficaz que a aprendizagem era realmente um sucesso. As outras alunas também gostavam muito da Professora Maria do Carmo, respeitavam-na. Sabiam que ela era exigente e que quando ela exigia era porque queria o bem da gente. Hoje a gente vê como foi bom o que ela fez. (ALMEIDA, 2013, p. 5)

São lembranças de relações harmonizadas no interior da escola, em um momento hostil em que medo e repressão se faziam presentes. Sabemos que, nesse período, os conflitos precisavam ser abafados. Assim, o sorriso para abafar a exigência. É possível que o sorriso fosse uma representação. A professora aprendeu o jogo e deu muito bem as cartas. Já havia perdido uma vez e a experiência serviu-lhe para não repetir as mesmas ações. De forma que:

A gente fazia um trabalho, assim, muito, como é que eu vou dizer [...] muito ligado. Porque a gente se afinava tanto na filosofia de trabalho, que com certeza ela tomaria a decisão que eu tomaria se estivesse presente. Então a escola funcionou muito bem nesse sentido, porque existia uma filosofia muito grande de trabalho, uma filosofia única e isso a gente sentia também nos professores. (OLIVEIRA, 2013, p. 7)

Mas em que consistia essa "filosofia de trabalho única", se o que tínhamos era a proposta educacional tecnicista? Estaria a proposta educacional realizada pela Professora Maria do Carmo de Miranda, e demais professores da escola normal de Santa Rita, reconfigurando os caminhos traçados para a educa- 
ção desse momento? Buscamos as respostas nas memórias:

Os professores trabalhavam com muita dedicação, com muito afinco, com muita boa vontade. Às vezes eu penso hoje como era que a gente conseguia levar a escola daquele jeito que a gente levava, porque não só na parte pedagógi$\mathrm{ca}$, administrativa, mas a gente participava muito da vida dos alunos. Eu me lembro que teve uma menina que casou e a gente ia ajudava nas coisas da festa do casamento, a escolher a roupa do casamento, nascia menino a gente ia, a gente participava muito da vida dos alunos. A escola tomou um aspecto muito grande de família, porque a gente conhecia (se fosse casado a gente conhecia o marido, os filhos, se fosse solteiro a gente conhecia os namorados). Vivia um relacionamento muito grande, muito bom. (OLIVEIRA, 2013, p. 8)

Diante dessas lembranças, nos deparamos com uma escola que adquiria aspecto de família, de participação na vida do aluno, certamente uma proposta educacional menos rígida do que o modelo educativo imposto pela legislação e pela política educacional do período, pois a filosofia única consistia no envolvimento, tanto na atividade docente, quanto nas relações pessoais, entre professores, equipe pedagógica e alunos. Indícios de uma leveza nas relações que perpassavam a escola atribuindo-lhe um sentimento de família, onde todos se conheciam e interagiam.

Nesse relacionamento "muito grande e muito bom" parecia que as tensões da ditadura ficavam para além dos muros da escola. Mas seria possivel, manter-se meio que inerte diante do modelo educacional marcado pela repressão punitiva, pela obediência e imposições? Compreendemos que essa sensação de "tranquilidade" vivenciada na escola normal, nesse momento, corroborava para o fortalecimento das ações ditatoriais.

Um fortalecimento que acontecia no silenciamento velado presente na "aparente tranquilidade dentro da escola", no sentido de que "quem cala consente", ou seja, diante de todas as pressões e violações instauradas, a escola parecia inerte a esses acontecimentos, tudo em ordem, como uma grande família, sem conflitos.

Ora, sabemos que a escola é um espaço de conflitos, de discussões, um espaço dialógico. Entre o sorriso e o consentimento, nada se contradiz, experimenta-se a passividade apassivadora da ausência de palavras e de ações. 0 magistério configurava-se nessa sensação de tranquilidade, no seio de uma grande família. Os ecos da resistência ao regime estavam do outro lado dos muros da escola.

Na escola pairava a sensação de tranquilidade, onde tudo parecia estar bem. Não existia espaço para questionar ou refletir sobre as medidas tomadas pela e para a ditadura civilmilitar? Com essa "tranquilidade aparente", a escola se mantinha inerte diante do cerceamento dos direitos pelo regime autoritário.

Diante dos caminhos traçados para a educação, as memórias sobre a história de vida professoral de Maria do Carmo de Miranda revelaram uma postura pedagógica mesclada pela exigência e disciplina, mas também envolvida pelo sentimento de amorosidade. Por tais razões, disciplina e rigor para seguir a ordem instaurada, já que contrariá-la era inviável se não impossível, e amorosidade para amar a alteridade - mesmo diante de restrições de direitos - e/ou para diminuir a sensação de insatisfação/tristeza perante as práticas autoritárias, foram "estratégias" adotadas pela Professora Maria do Carmo de Miranda, no exercício docente, durante a ditadura civilmilitar.

Nessas memórias, nos encontramos com esboços do fazer pedagógico da Professora Maria do Carmo de Miranda, ${ }^{5}$ que foram revelados a partir das representações entre lem-

5 A Professora Maria do Carmo de Miranda faleceu em 07 de setembro de 1988. 
brar e esquecer. Nesse sentido, no desvelar da prática professoral da docente, nos deparamos com lembranças resumidas à pessoa e à profissional.

Percebemos, então, que a história de vida professoral de Maria do Carmo de Miranda, sua biografia, está envolta pela representação da professora bondosa, que mesmo com uma postura exigente, disciplinada, mesclava o sorriso e a amizade. Nesse cenário autoritário, ser a "professora boa" significava não se impor às ordens estabelecidas, não contestar, realizar o trabalho pedagógico de forma rápida e eficiente, preparar os alunos para o mercado de trabalho a partir da tendência tecnicista.

É a partir das memórias de Eliete Oliveira (2012) que chegamos à Escola Normal Professora Maria do Carmo de Miranda, nos anos de 1986, quando a Escola se chamava Escola Normal Ministro Pereira Lira:

Quando eu cheguei aqui na escola, Maria do Carmo não estava. Quem me recebeu foi a adjunta, pegou minha portaria. Depois ela me apresentou, eu sou a adjunta, mas ela é a diretora, todos os problemas você vai passar pra ela. E ela só fazia rir. Maria do Carmo só ria. Eu lembro, aquele rostinho bem afiladinho, o cabelo bem fininho, magrinha, gostava de andar de salto. Até hoje a gente diz olha a zuada desse salto aí, acho que é Maria do Carmo que tá por aí. E foi assim. (OLIVEIRA, 2012, p. 5)

Diante dessas lembranças, repensemos a representação da diretora desse momento, qual o significado da própria adjunta dizer "eu sou a adjunta, mas ela é a diretora"; o que está por trás da expressão "todos os problemas você vai passar pra ela", a diretora seria a pessoa que resolvia todos os problemas da escola ou aquela que centralizava todas as decisões. $O$ que era ser a diretora nesse momento em que o país, e a cidade de João Pessoa/PB entravam no processo de abertura democrática pós-ditadura civil-militar, em que os papéis escolares também eram revistos.
Nessa atitude de silenciar e sorrir, a Professora Maria do Carmo de Miranda afirmavase enquanto uma diretora ao mesmo tempo exigente e sensivel, pois seu silêncio diante da fala da diretora adjunta (que hierarquicamente se coloca numa posição menos importante diante dos problemas da escola, ou seja, "sou a adjunta", como se dissesse não sou eu quem resolve as coisas) reforçava os atributos controladores que cercavam a denominação ser “a diretora" desse momento.

Tais características podem ser percebidas na primeira reunião pedagógica realizada pela Professora Maria do Carmo de Miranda na Escola:

(07/04/1986) Primeira reunião realizada pela Diretora com o corpo docente, objetivando:

Conhecer os doze professores;

Distribuir as disciplinas entre os professores;

Informar sobre a filosofia de trabalho;

Dar conhecimento sobre o Parecer no 349/1972; Informar sobre a sistemática de trabalho; Informar sobre a estrutura física da Escola; Apresentação dos auxiliares administrativos. (ALVERGA, 1986, p. 4)

Nessa reunião, a Professora buscava estabelecer contato com os professores, de forma a "conhecê-los", o que pressupõe uma atitude mais próxima, menos hierárquica, porém, ao mesmo tempo, percebemos uma atitude reguladora quando na reunião o verbo informar se faz presente. Assim, os professores seriam informados, dentre outros assuntos, sobre a filosofia de trabalho, ou seja, esta filosofia de trabalho não seria discutida junto com os professores, pois já estava determinada pela diretora.

Essa situação, vivenciada no ano de 1986, ou seja, pós-ditadura, nos revela que o espaço ainda era de pouca abertura para a reflexão pedagógica, vivenciando a sociedade um momento de transição entre ditadura e (re)democratização. 
Assim, a filosofia de trabalho e as práticas pedagógicas e administrativas da escola normal de João Pessoa/PB estavam mescladas pelo autoritarismo e por alguns elementos que já demarcavam os novos tempos, como a proposta de preparação do educador, e não apenas do professor, enquanto diretriz principal da escola.

De acordo com os objetivos da Escola Normal, a formação para o Magistério, é a formação para o Magistério de 1a a 4a série do 1o grau, a diretriz principal da Escola Normal Estadual Ministro Pereira Lira é a formação do educador e não, simplesmente, a formação do professor, entendendo-se educador aquele que aceita e ama o seu trabalho e preocupa-se não somente em dar instrução, mas, sobretudo, formar a personalidade do aluno em todas as suas dimensões. (ALVERGA, 1986, p. 4)

$\mathrm{Na}$ segunda reunião, realizada doze dias após a primeira, a Professora Maria do Carmo de Miranda propôs avaliar a primeira semana de trabalho, entre outras atividades conforme consta no "Livro de ocorrências das atividades administrativas e pedagógicas da escola":

Segunda reunião realizada pela Diretora, dia 19.04.86, objetivando:

Avaliar a primeira semana de trabalho;

Diagnosticar a clientela;

Discutir o horário dos professores;

Estabelecer aulas aos sábados;

Dividir os bimestres;

Colher os endereços dos professores;

Comentar sobre os departamentos, a divisão por área, o horário departamental, os coordenadores por área. São quatro departamentos: Área de Formação Especial, Área de Comunicação e Expressão, Área de Estudos Sociais, Área de Ciências.

Comentar sobre os serviços da Escola e seus objetivos: Serviço de Orientação Educacional/
SOE, Prática de Ensino, Centro Artístico, Centro Cívico.

Discutir sobre o fardamento dos alunos. Ficou acertado que a farda seria composta de calça jeans, tênis azul e branco, ou branco, blusa branca ou azul e branca, a ser escolhida definitivamente pelos alunos. Observação: posteriormente os alunos votaram pela blusa branca com o logotipo elaborado pelo professor.

Distribuir as salas de aula;

Comentar a integração que deve existir entre os professores da própria área e das áreas entre si;

Desencadear uma campanha de doação de livros para a escola.

(ALVERGA, 1986, p. 5)

Diante do curto intervalo de tempo, doze dias após a primeira reunião, da existência de um "Livro de Ocorrências", e da quantidade de questões tratadas nessa segunda reunião, podemos notar a postura de trabalho "controladora e exigente" da Professora Maria do Carmo de Miranda, que, após uma semana, praticamente, reúne professores e demais funcionários, para avaliar a primeira semana de trabalho. É interessante observar que avaliar os trabalhos desenvolvidos na primeira semana foi o assunto de abertura da reunião, o que demonstra que para a Professora Maria do Carmo de Miranda acompanhar e avaliar o trabalho realizado era atividade importante, pois, através da avaliação, poderia rever ou melhorar possiveis falhas ou desacertos.

Outro indício da atuação pedagógica da Professora Maria do Carmo de Miranda, além de diagnosticar o público de alunos, foi a campanha de arrecadação de livros. Essa proposta aponta duas situações, seu interesse pela leitura e sua percepção da importância da leitura para a educação, diante da insuficiência de material didático desse momento. É o que nos revelam as memórias de Eliete de Oliveira (2012, p. 6), quando afirma: 
A Professora Maria do Carmo de Miranda foi uma pessoa muito batalhadora, muito lutado$\mathrm{ra}$, batalhadora mesmo. Ela lutou tanto porque nesse tempo não tinha carro, hoje na Secretaria tem carro pra trazer, naquele tempo não tinha. Ela lutava para o pessoal trazer material pra essa escola, material de limpeza, livro, era tudo muito dificil. Ela lutou bastante pra conseguir as coisas.

Quanto ao sorriso, este se tornava uma das marcas da Professora Maria do Carmo de Miranda, conforme podemos perceber nas lembranças das pessoas que com ela trabalharam:

Maria do Carmo era uma pessoa altamente inteligente. Uma pessoa boa, de uma formação. Ela vivia sorrindo, para ela não tinha dias ruins. Uma pessoa maravilhosa. Ela se dedicou tanto a escola, não tinha hora de almoço, o tempo todo com a pressão alta, a gente dizia Carminha cuidado, mas infelizmente [...]. (SEIXAS, 2013, p. 2)

Mas o que significava ser considerada uma pessoa altamente inteligente? No sentido de se fazer atender dos dois lados: pessoas da escola e Secretaria de Educação, ou seja, ela conseguiu conquistar tanto os funcionários da escola como as pessoas da Secretaria de Educação do Estado. Esse fato tornava mais fáceis as relações e a aquisição de recursos junto ao Órgão de Educação, bem como o envolvimento dos funcionários da escola no trabalho.

O sorriso da Professora Maria do Carmo de Miranda reaparece nas memórias de Carleide de Oliveira (2013, p. 2): "Sempre com um sorriso nos lábios. E aquilo contagiava a gente". E quando perguntamos à entrevistada sobre as lembranças que ficaram da Professora, a resposta foi a seguinte:

Boas lembranças. Só um sorriso. E quando ela chegava pra conversar com a gente com aquele sorriso nos lábios, e quando tínhamos uma reunião ela chegava com uma poesia 'sorrir, sorrir'. Ainda vou ter a oportunidade de lhe dar a poesia que eu guardei, que ela dava a gente, até hoje eu guardei. (OLIVEIRA, C., 2013, p. 3)
Diante dessas memórias, compreendemos o esquecimento sutil da atuação pedagógica vivenciada nos anos de 1986, de forma que $a$ pessoa, o jeito de ser da Professora Maria do Carmo de Miranda, se sobrepõe a sua atuação pedagógica. Nesse depoimento, o caráter seletivo da memória é percebido. As memórias de Carleide de Oliveira selecionaram como importantes para serem guardadas: a forma de ser da Professora Maria do Carmo de Miranda, representada pela poesia que ela mais gostava, o gesto de um sorriso, as relações de amizade, e não o que era discutido nas reuniões pedagógicas, por exemplo.

As escolhas da memória nos permitem pensar que a relação entre a pessoa do professor, ou seja, as formas de ser e de viver influenciam na forma de ser professor, em sua ação pedagógica. Assim, quem seria a professora? E quem seria a pessoa? Quem estava mais presente em sua forma de ser?

As memórias desveladas sobre a vida professoral de Maria do Carmo de Miranda nos revelam que seu jeito de ser pessoa - bondosa, amiga, sorridente, compreensiva, mas também rigorosa - dialogava com sua forma de ser professora.

Em alguns momentos, adotou posturas democráticas de enfrentamento, a exemplo da greve dos professores de 1987, em que “A Diretora da Escola [Maria do Carmo de Miranda] reuniu os professores para discutir problemas de ordem administrativa e pedagógica. Em face da situação do funcionalismo estadual, em greve, propôs-se adiar os trabalhos aderindo à greve geral" (ALVERGA, 1986, p. 32).

O que corrobora com o fato de que quando era preciso sorrir ela sorria, quando era preciso lutar, ela lutava. Conforme constatamos nas memórias de Patrício (2013, p. 8): “Se não fosse ela talvez a gente nem tivesse o salário mínimo da gente. Realmente a gente entrou no tempo de Burity e ele tirou a gente. $E$ a gente foi tudo 
pra rua, e ela foi e adquiriu a gente tudo de volta". O que demonstra a influência da Professora Maria do Carmo de Miranda no meio político daquela época e sua experiência nos impasses políticos.

\section{Considerações finais}

A constituição da identidade professoral no período estudado corrobora com os preceitos de Nóvoa (2007), enquanto um lugar de conflitos, movimento complexo e ao mesmo tempo dinâmico. Situação que não significa a negação da identidade pessoal, mas sim o enlace entre o eu pessoal e o eu profissional, tendo em vista que "O professor é a pessoa; e uma parte importante da pessoa é o professor" (NÓVOA, 2007, p. 15).

Diante de um contexto autoritário, caracterizado pelos mandos e desmandos políticos, a problematização da história de vida da Professora Maria do Carmo de Miranda, do saber docente elaborado e (reproduzido), viabilizado/inviabilizado pelo poder/interesse político local, relata-nos momentos da história da educação e da docência paraibana no período investigado.

Tanto a identidade professoral, quanto o saber docente desenvolvido pela Professora Maria do Carmo de Miranda foram envolvidos/ marcados pela influência política e a perseguição partidária, de forma que, como tantas outras professoras de sua época, aprendeu a lidar com as artimanhas do cenário que a envolveu, ora driblando ou reforçando, ora resistindo às influências da política local/nacional no interior da escola.

A inexistência de concurso público para professor (e demais cargos públicos), apesar da regulamentação da LDB 4.024/1961, era um forte agravante da situação controvertida vivenciada na educação da época, pois reforçava a influência política na composição do corpo de funcionários do sistema escolar, demonstrando o desinteresse pela educação e pela carreira docente.

\section{Referências}

ALMEIDA, Jane Soares de. Mulheres na educação: missão, vocação e destino? A feminização do magistério ao longo do século XX. In: SAVIANI, Demerval et al. (Orgs.). 0 legado educacional do século XX no Brasil. Campinas, SP: Autores Associados, 2006.

ALMEIDA, Elza de Souza. Elza de Souza Almeida: depoimento [agosto. 2013]. Entrevistador: Maria das Graças da Cruz Barbosa. João Pessoa: 2013. Suporte digital MP3.

ALVERGA, Naide Ribeiro de. Livro de Ocorrências Administrativas e Pedagógicas da Escola Estadual Ministro Pereira Lira. João Pessoa, 1986. (Acervo da Escola Normal Professora Maria do Carmo de Miranda, aos cuidados de Carleide de Oliveira Cavalcante).

BRASIL. Lei de Diretrizes e Bases da Educação Nacional. Lei no 4.024 de 20 de dezembro de 1961. Disponivel em: <http://www.pdf4free.com>. Acesso em: 20 nov. 2012a.

BRASIL. Lei Orgânica do Ensino Normal. Decreto-lei no 8.530/1946. Brasília, 1942. Disponível em: <http:// www2.camara.leg.br/legin/fed/declei/1940-1949/ decreto-lei-8530-2-janeiro-1946-458443-publicacaooriginal-1-pe.html >. Acesso em: 13 jul. 2012b.

BRAUDEL, F. 0 mediterrâneo e o mundo mediterrâneo na época de Felipe II. São Paulo: EDUSP, 2016.

DELGADO, Lucilia de Almeida Neves. História oral: memória, tempo, identidades. 2. ed. Belo Horizonte: Autêntica, 2010.

DOSSE, François. 0 desafio biográfico: escrever uma vida. Tradução de Gilson César Cardoso de Souza. São Paulo: Edusp, 2009.

ESQUISANI, Rosimar S; WERLE, Flávia O. C. Ser professora: um estilo de vida pontuado pela formação. Revista HISTEDBR On-line, Campinas, n. 38, jun. 2010. 
FEBVRE, L. Martinho Lutero, um destino. São Paulo: Três Estrelas, 2017.

FONTANA, Roseli A. Cação. Como nos tornamos professoras? São Paulo: Autêntica, 2007.

GINZBURG, Carlos. Mitos, emblemas, sinais: morfologia e história. São Paulo: Companhia das Letras, 1989.

GOMES, Jandynéa de Paula Carvalho. A profissionalização dos professores na Parahyba do Norte (18341889). In: PINHEIRO, A. C. F.; FERRONATO, Cristiano de Jesus. (Orgs.). Temas sobre a instrução pública no Brasil imperial (1822-1889). João Pessoa: Editora Universitária/UFPB, 2008.

HALBWACHS, Maurice. A memória coletiva. Tradução de Beatriz Sidou. 2. ed. São Paulo: Centauro, 2006.

HARTOG, François. Evidência da história: o que os historiadores veem. Belo Horizonte: Autêntica, 2011.

LE GOFF, Jacques. História e memória. Tradução Bernardo Leitão (et al). 6. ed. Campinas, SP: Editora da Unicamp, 2012.

MELLO, José Octávio de Arruda. História da Paraíba: lutas e resistência. 11. ed. João Pessoa: A União, 2008.

MIGNOT, Ana Chrystina Venancio. Editando o legado pioneiro: o arquivo de uma educadora. In: MIGNOT, A. C. V.; BASTOS, M. H. C.; CUNHA, Maria Teresa Santos. (Orgs.). Refúgios do eu: educação, história, escrita autobiográfica. Florianópolis: Mulheres, 2000.

NAPOLITANO, Marcos. 1964: História do regime militar brasileiro. São Paulo: Editora Contexto, 2014.

NÓVOA, António. (Org.). Vida de professores. 2. ed. Porto: Editora Porto, 2007.

Os professores e as suas histórias de vida. In: NÓVOA, António. (Org.). Vidas de professores. 2. ed. Porto: Editora Porto, 1999.

OLIVEIRA, Maria da Penha Lopes Soares de. Maria da Penha Lopes Soares de Oliveira: depoimento [Ju- nho. 2013]. Entrevistador: Maria das Graças da Cruz Barbosa. João Pessoa: 2013. Suporte digital MP3.

OLIVEIRA, Carleide Cavalcante de. Carleide Cavalcante de Oliveira: depoimento [julho. 2013]. Entrevistador: Maria das Graças da Cruz Barbosa. João Pessoa: 2013. Suporte digital MP3.

OLIVEIRA, Eliete Lima de. Eliete Lima de Oliveira: depoimento [julho. 2012]. Entrevistador: Maria das Graças da Cruz Barbosa. João Pessoa: 2012. Suporte digital MP3.

PASSEGI, Maria da Conceição; SILVA, Vivian Batista da. (Orgs.). Invenções de vida, compreensão de itinerários e alternativas de formação. São Paulo: Cultura Acadêmica, 2010.

PATRÍCIO, Fátima de Lurdes Ribeiro. Fátima de Lurdes Ribeiro Patrício: depoimento [junho. 2013]. Entrevistador: Maria das Graças da Cruz Barbosa. João Pessoa: 2013. Suporte digital MP3.

PESAVENTO, Sandra Jatahy. História e história cultural. 2. ed. Belo Horizonte: Autêntica, 2005.

ROMANELLI, Otaíza de Oliveira. História da educação no Brasil (1930/1973). 4. ed. Petropólis, RJ: Vozes, 1983.

SANTOS, Maria da Consolação Miranda dos. Maria da Consolação Miranda dos Santos: depoimento [junho. 2013]. Entrevistador: Maria das Graças da Cruz Barbosa. João Pessoa: 2013. Suporte digital MP3.

SEIXAS, Rosélia Maria do Egito. Rosélia Maria do Egito Seixas: depoimento [junho. 2013]. Entrevistador: Maria das Graças da Cruz Barbosa. João Pessoa: 2013.

VEIGA, Greive Cynthia. História da educação. São Paulo: Ática, 2007.
Recebido: 08.01.2018

Aprovado em: 30.07.2018 
Maria Graça Cruz Barbosa é Pós-Graduanda em Gestão Pública Municipal, pela Universidade Federal da Paraíba/UFPB. Mestre em Educação pelo Programa de Pós-Graduação em Educação da Universidade Federal da Paraíba/PPGE/UFPB e em Direitos Humanos pelo Programa de Pós-Graduação em Direitos Humanos, Cidadania e Políticas Públicas da Universidade Federal da Paraíba/PPGDH/UFPB. Professora da Secretaria de Educação do Município de Bayeux/PB. e-mail: gracacruz25@hotmail.com

Av. Liberdade, 3720, Centro. Bayeux/PB. CEP: 58306-001. Fone: (83) 98639-7615.

Luciana Martins Teixeira Santos é Pós-Graduanda em Gestão Pública Municipal, pela Universidade Federal da Paraíba/ UFPB. Mestra em Direitos Humanos pelo Programa de Pós-Graduação em Direitos Humanos, Cidadania e Políticas Públicas da Universidade Federal da Paraíba/PPGDH/UFPB. Professora da Secretaria de Educação do Município de João Pessoa/PB. e-mail: lucianamartins.teixeira@hotmail.com

Rua Diógenes Chianca, 1777, Água Fria, João Pessoa/PB. CEP: 58053-900. Fone: (83) 98804-4773.

Maria Elizete Guimarães Carvalho é Doutora em Educação pela Universidade Federal do Rio Grande do Norte/UFRN. Pós-Doutora em Política Educativa pela Universidade do Minho/PT. Professora Associada da Universidade Federal da Paraíba/UFPB. Departamento de Fundamentação da Educação, Centro de Educação. Credenciada aos Programas de Pós-Graduação em Educação/PPGE/UFPB e em Direitos Humanos/PPGDH/UFPB. Pesquisadora do Grupo de Estudos e Pesquisas História da Educação Brasileira, GT - PB. e-mail: mecarvalho23@yahoo.com.br

Av. Rui Barbosa, 1488, Lagoa Nova, Natal/RN. CEP: 59.065-300. 